\title{
Effect of adherend recessing on bi-adhesively bonded single-lap joints with spew fillet
}

\author{
AHMET ÇALIK $^{1, *}$ and SEFA YILDIRIM ${ }^{2}$ \\ ${ }^{1}$ Department of Mechanical Engineering, Adana Science and Technology University, Adana, Turkey \\ ${ }^{2}$ Department of Mechanical Engineering, Faculty of Architecture and Engineering, Çukurova University, \\ 01330 Balcal1, Adana, Turkey \\ e-mail: acalik@cu.edu.tr
}

MS received 30 November 2014; revised 23 May 2016; accepted 27 September 2016

\begin{abstract}
The effect of adherend recessing on the strength of full (spew)-fillet-formed bi-adhesively bonded single-lap joint (SLJ) was investigated using the finite-element (FE) method under pure tension (i.e., 20 dissimilar recess length and depth and two-type bi-adhesive bond). A three-dimensional (3D) FE model was developed for bi-adhesively bonded SLJ, which had fillet and recessed adherend, assuming that both adhesive and adherend have geometrical non-linearity and exhibit linear material behaviour. The novelty of present study is the application of recessing process on the fillet-formed bi-adhesively bonded SLJs. The bondline characteristics of bi-adhesively bonded joints with the effect of adherend recessing have been investigated by examining the distributions of the peel and maximum principle stresses (MPS) at the mid-plane of the bondline. The results from the FE simulations in which varying geometric parameters are used reveal that the combined effects of adherend recessing spew fillet and bi-adhesive bondline led to a major decrease in the peak values of the peel stress, which is the governing failure stress and MPS. A novel design that may be beneficial to improve the strength characteristics of aluminium SLJ is presented.
\end{abstract}

Keywords. Bi-adhesive; adherend recessing; spew fillet; single-lap joints; finite-element method.

\section{Introduction}

Adhesively bonded joints have been found in many applications of engineering in the automotive, aerospace, marine and medical industries [1-3] owing to their good strengthweight and cost-effectiveness ratios, fatigue and corrosion resistance and adhesive capabilities to join very thin adherends and different materials. The single-lap joint (SLJ) is the most common bonding method with its simplicity and bending moment that occurs due to the eccentric loading; however, additional normal stresses are observed within the bondline, which decrease the joint strength and may result in a failure [4].

The joint geometry has a major effect on the strength characteristics, which are also influenced by different boundary conditions. For analytical solution, obtaining an overall system of governing equations for predicting the mechanical properties of the adhesively bonded joints becomes very difficult due to the rather complex joint geometry and its three-dimensional (3D) nature [5]. In the analytical method, some assumptions such as constant peel stress distribution through the adhesive thickness and restricted transverse deformations in the adherends should be

*For correspondence required to simplify the models in order to be formulated. As a consequence, application of the analytical solutions should be in a simple geometry without fillets, recess, slots, etc. On the other hand, experiments, which require specific equipment and skilled technicians, remain cumbersome and are costly. Therefore, the finite-element (FE) analysis has frequently been used for many years in order to investigate effect of different geometries and adhesives on an adhesively bonded joint under various load conditions [5, 6].

Two main categories may be defined considering the parameters that influence the stress distributions in the bond region. The first is known as material parameters, which include the adherend and the adhesive material properties. The second is geometric parameters such as the adhesive layer thickness, the adherend thickness and the overlap length [7].

Different ideas concerned with both adhesive and adherend have been investigated to enhance the bond characteristics of joints [8-10]. Several studies on the optimization of SLJs by spew fillet and different spew geometries may be cited [2, 11-13].

Fessel et al [14] studied numerically how the joint geometry is effective for enhancing the strength of joint and they conducted an experiment in order to support their results. They showed that using a reverse bent increases the strength properties compared with a conventional lap joint. 
Pires et al [15] presented a numerical study and they obtained an improvement in the joint strength using hybrid adhesives compared with the cases of single adhesives in the bond region.

The mechanical behaviour of the lap and scarf joints subjected to tensile impact loading was studied by Sato and Ikegami [16] analytically and experimentally. The study showed that the stress concentration and stress variations of scarf joints are lower than those of both single-lap joints (SLJs) and tapered lap joints.

The effect of variation of adhesive modulus in hybrid adhesively bonded SLJ was studied both experimentally and numerically by Fitton and Broughton [17]. They concluded that using the adhesive with high shear strength at the centre of the bondline decreases the stress values and leads to good strength properties.

An FE analysis was conducted by Adin and Temiz [18], where the stress-strain behaviours throughout the bond length and adherend thickness in double-lap joints under tensile loads were investigated.

Aydin et al [19] investigated the bond area behaviour of hybrid bonded SLJs under a bending moment experimentally and numerically.

Another experimental and numerical study was presented by Tang et al [20], where the static and fatigue behaviours of thick composite laminate single-lap adhesive joints were analysed. They observed that increasing the bondline thickness decreases both static and fatigue strength values and also the failure begins at the interface between adhesive and adherend.

Also Ozel et al [21] investigated the effect of geometric variations of lower and upper adherends of adhesively bonded SLJ subjected to tensile loading experimentally and numerically.

Akpinar et al [22] applied protrusion to SLJs for two different loading conditions. In the first condition the SLJ is subjected to tensile load and in the second condition it is bending loading. It is observed that the protrusion increases the strength of the joint in the condition in which it was subjected to bending load, in contrast with the condition in which it was under tension.

Apalak et al [23] used the FE method in order to study the stress and stiffness behaviours of adhesively bonded tee joints with a single support plus angled reinforcement.

Strength characteristics of different SLJ configurations in tension derived from adherends with different thicknesses were studied experimentally and numerically by Gültekin et al [24]. They showed that in SLJ geometry, variations of the lower and upper adherend thickness affect the stress concentrations at the edges of the overlap regions; however, increasing the adherend thickness does not improve the failure load of the joints.

İşcan [25] studied the stress behaviour of double-strap joints under tensile load numerically and experimentally. It is shown that a decrease in the stress values of the adhesive layer is observed with an increase in the height of the embedded cover plate.

Solmaz and Topkaya [26] conducted a progressive failure analysis on adhesively riveted and hybrid bonded double-lap joints and they showed that an enhancement on the mechanical properties of the joint was obtained with increase of the overlap distance.

Pinto et al [27] conducted an experimental and numerical analysis with the aim of evaluating the effect of adherend recessing at the overlap edges on the tensile strength of SLJ, bonded with a brittle adhesive.

In this work, two different single-lap bi-adhesive joint models where both models have various recess geometries were examined in order to understand the combined effect of varying recess geometry and bondline configuration on the peaked peel stress and maximum principle stresses (MPS) at the adhesive midline.

\section{Description of the finite-element model}

The material properties of determined adherend (aluminium) and adhesives (Terokal 5045 and Hysol EA 9313) are listed in table 1. Terokal 5045 were used as a flexible adhesive and Hysol EA 9313 as a stiff adhesive.

The determination of adherend and adhesive materials was specified according to the practical use in the engineering applications and literature [28] [29]. Also, the positioning of flexible and stiffer adhesives is adjusted based on the study of Kumar and Pandey [30], which shows that the joint strength can be enhanced using an adhesive with low modulus at the ends of overlap in a bondline, which leads to a major decrease in the stress concentration.

The boundary conditions and dimensions of bi-adhesively bonded SLJ design are shown in figure 1 . In this figure, $D$ and $L$ are depth and length of the recessing, $F$ is one of the edges of the spew fillet, formulated as $t+k-D$ where $t(0.2 \mathrm{~mm})$ and $k(2 \mathrm{~mm})$ are the thickness of the adhesive and the adherends, respectively. In the analyses of the adhesive mid-bondline, the formula for total overlap length was defined as $S+2 B$ and it was taken as $12.5 \mathrm{~mm}$. Also the joint width was set as $25 \mathrm{~mm}$. The other geometric dimensions of both models are presented in table 2 .

Table 1. Material properties of adhered and adhesives.

\begin{tabular}{lccc}
\hline & Aluminium & $\begin{array}{c}\text { Stiff } \\
\text { adhesive }\end{array}$ & $\begin{array}{c}\text { Flexible } \\
\text { adhesive }\end{array}$ \\
\hline $\begin{array}{l}\text { Young's modulus } \\
\text { (MPa) }\end{array}$ & 71,700 & 2274 & 437.4 \\
$\begin{array}{c}\text { Shear strength } \\
\text { (MPa) }\end{array}$ & 152 & 27.6 & 20 \\
\begin{tabular}{l} 
Poisson's ratio \\
\hline
\end{tabular} & 0.33 & 0.36 & 0.38 \\
\hline
\end{tabular}



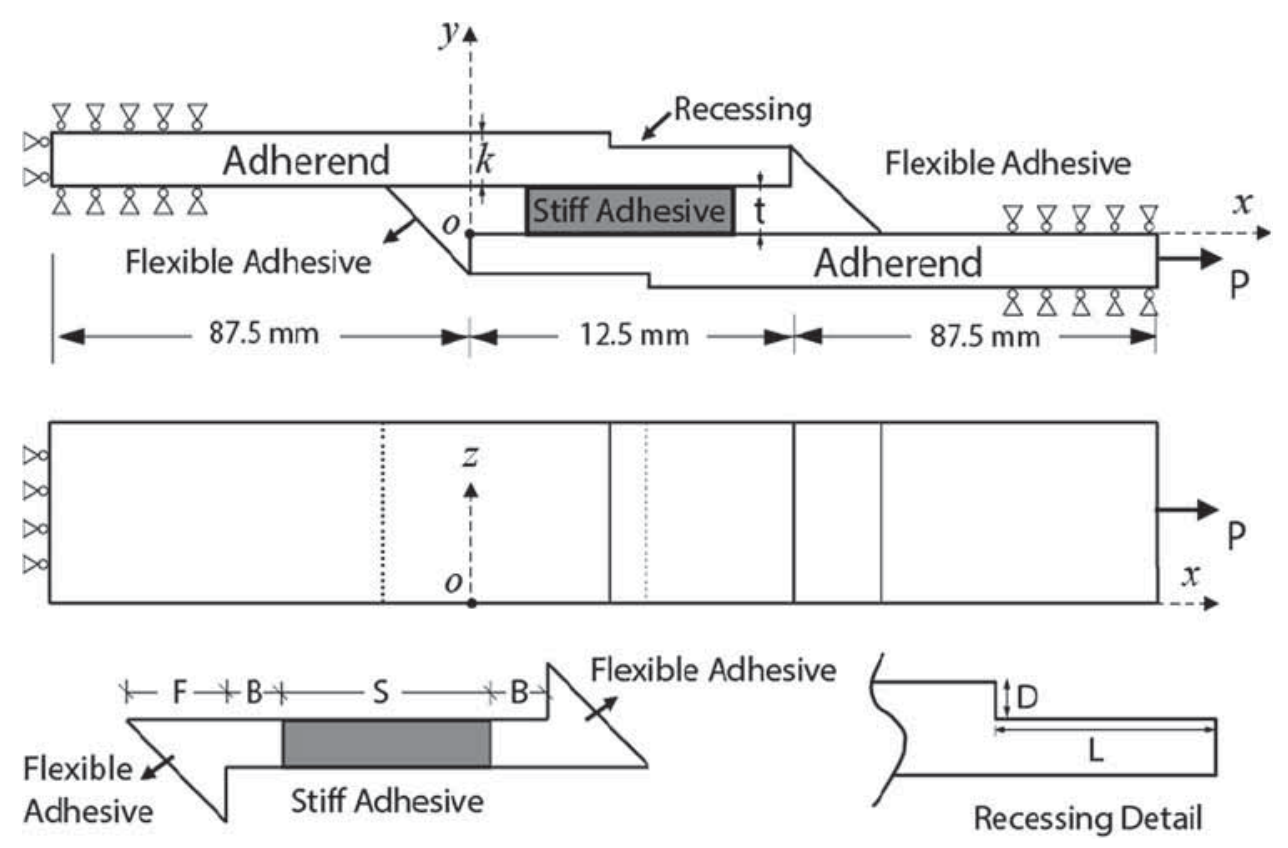

Figure 1. Geometric model and loading condition of spew-filled bi-adhesively bonded SLJ.

Table 2. Geometric dimensions of studied models.

\begin{tabular}{|c|c|c|}
\hline & Case 1 (25-75-25 Model) & Case 2 (35-55-35 Model) \\
\hline$S(\mathrm{~mm})$ & 7.5 & 5.5 \\
\hline$B(\mathrm{~mm})$ & 2.5 & 3.5 \\
\hline
\end{tabular}

In the models, the first and the last number (25-25 for the first model and 35-35 for the second model) denote the length of flexible adhesives and the second number ( 75 for the first model and 55 for the second model) denotes the length of stiff adhesive in decimillimetres.

The SLJ was meshed by ANSYS using tetrahedral and quadrilateral elements and the whole mesh of the SLJ consisted of 282,262 isoparametric elements with $1,382,586$ nodes. Tetrahedral elements were used in the fillet location due to equilateral triangle fillet geometry, and quadrilateral elements were used in the rest of the mesh (see figure 2). Elements on the critical points in adhesive layer such as ends of overlap region were densely placed due to the stress concentration. Also from the analyses, it was seen that increasing the number of elements over the defined value did not have a considerable effect on the results whereas it led to a dramatic increase in processing time. Also the SLJs subjected to tensile load have an eccentric loading path, which causes geometric non-linearity [31]. Geometrically non-linear FE analyses were conducted to consider the large rotations that take place in the joint using ANSYS finite-element (FE) commercial software.

The tensile load $(P)$, which is applied at the end of the lower adherend, is $1.8 \mathrm{kN}$. All degrees of freedom are restrained at the upper adherend end and also at the loaded end of lower adherend except for longitudinal displacements. The details are depicted in figure 1 . (a)

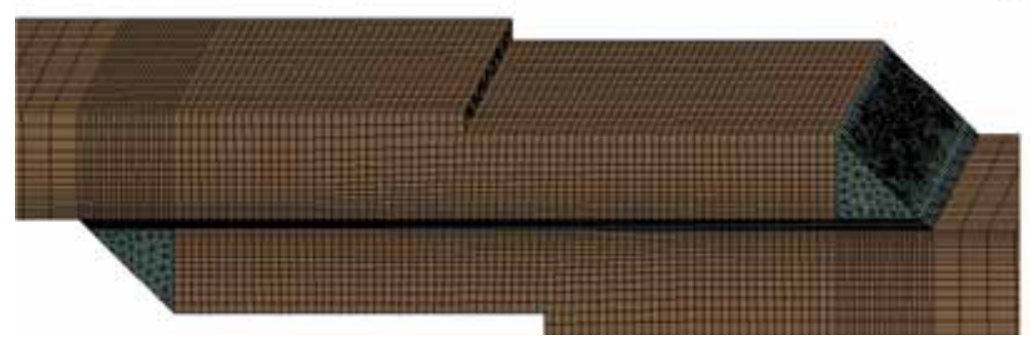

(b)

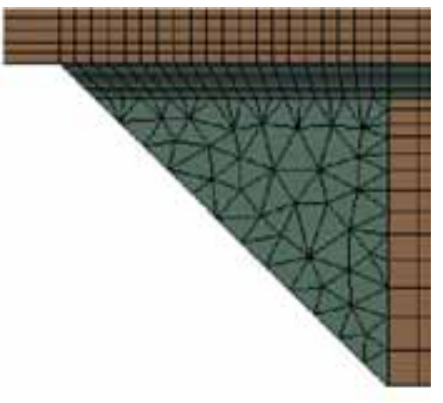

Figure 2. (a) 3D mesh model and (b) detailed view of the finite-element model. 

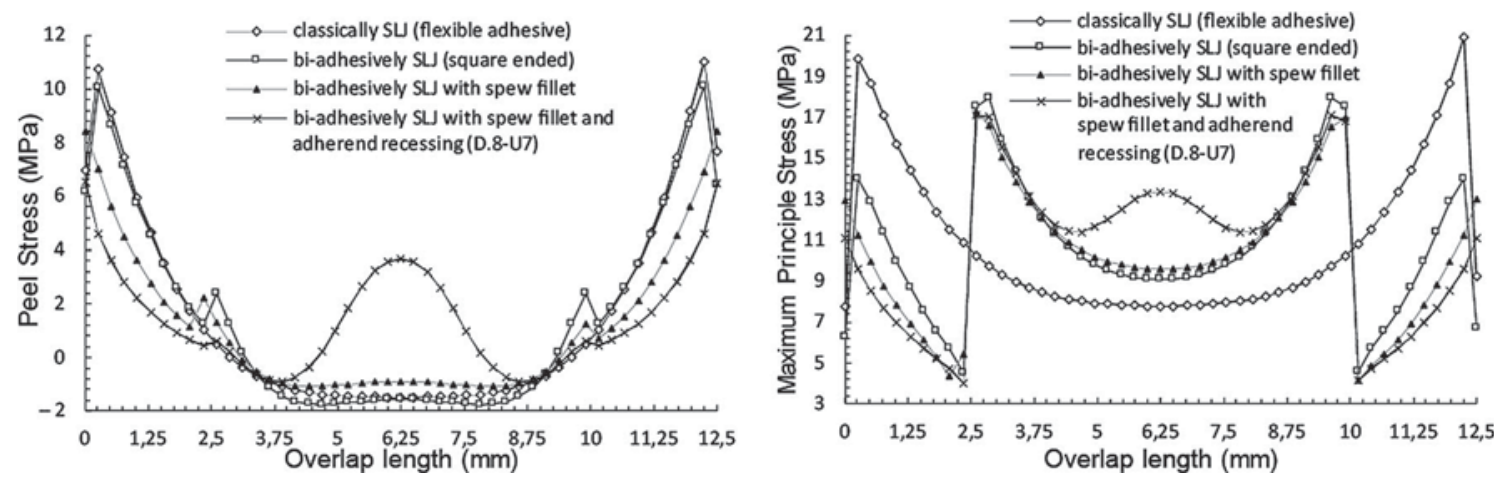

Figure 3. Effect of the pure spew fillet, bi-adhesives, adherend recessing and the combination of these on the bi-adhesively bonded lap joint.

In this investigation, the influences of the recess dimensions (depth $D$ and length $L$ ) on stress distributions (normal stress and MPS) of mid-bondline of two different bi-adhesively bonded joints composed of a combination of flexible and stiffer adhesives, and aluminium adherends, were studied.

The recessing process was applied at the free end of adherends in order to reduce the stress concentration on both ends of bond area.

In what follows, 40 different joint configurations are examined. Four different recess lengths $(L=6,7,8$ and 9 $\mathrm{mm}$ ) were used for both models and the influence of five different recess depths $(D=0.4,0.5,0.6,0.7$ and $0.8 \mathrm{~mm})$ on the strength of joints was investigated for each recess length.

As shown in figure 1, the location of the origin of the $x$ coordinate is at the top of the lower adherend and the location of the origin of the $y$ coordinate is at the left edge of the fillet.

\section{Results and discussion}

It is known that the peel and shear stresses, which are (mostly the peel) the main factors for failure, have a significant effect on the structural design of the lap joints. The optimal design is crucial for obtaining good strength properties; therefore the lap joints should be designed to induce low peel and shear stresses. However, in this study, it was observed that the shear stress values of each configuration remained constant with the variation of geometric parameters such as recess dimensions; hence peel stress and MPS were taken into consideration.

The analysis showed that the peel stress changes along the transverse coordinate $(z)$. The peak value of the peel stress is observed at $z=12.5 \mathrm{~mm}$ (width of the bond is 25 $\mathrm{mm}$ ); therefore the results obtained from the mid-plane of the adhesive were taken into consideration.

As seen in figure $3 a$ and $b$, the MPS in the stiff adhesive part of the bi-adhesive bondline is higher than that in the flexible adhesive part of the bi-adhesively bonded joint.
In figure 3, comparisons of the peel stress distributions of the mid-bondline of spew-fillet-bonded bi-adhesive joint and square ended (without fillet) bi-adhesively joint show that $13.7 \%$ stress reduction can be obtained at the confluence line of stiff and flexible adhesive of the joint with the application of spew fillet. Also the maximum values of peel stress and MPS in the bondline of the bi-adhesive with spew fillet model were $16.3 \%$ and $4 \%$ lower than in biadhesive without filled (square ended) model. In other words, the spew fillet resulted in $16.3 \%$ and $4 \%$ reduction on the peel stress and MPS, respectively. Similarly, adherend recessing caused $22.5 \%$ and $1 \%$ decrease on stress values in the joints having spew fillet. Also peel stress and MPS of conventional bi-adhesively bonded SLJ could be decreased markedly using both adherend recessing and spew fillet by $40.5 \%$ and $18.5 \%$, respectively.

In figure 4 , the abscissas are -2.5 and $15 \mathrm{~mm}$ for the end of left and right fillet, respectively. They are 2.5 and 10 $\mathrm{mm}$, respectively, for the left and right confluence interface between the stiff and flexible adhesives and 0 and $12.5 \mathrm{~mm}$ for the ends of lower and upper adherend.

In figures 5 and 6 the effects of recessing (depth $=0.4-0.8 \mathrm{~mm}$ and length $=1-4 \mathrm{~mm}$ ) on the stress distribution of joint with bi-adhesive bond composed of stiff adhesive (length $=5.5$ and $7.5 \mathrm{~mm}$ ) and flexible adhesive (length $=2.5$ and $3.5 \mathrm{~mm}$ ) in the mid-bondline $(y=0.1 \mathrm{~mm})$ are presented.

These processes were investigated as two different cases using varying geometrical parameters.

\subsection{Case 1}

In this case, the stiff adhesive bondline (S) was determined as $7.5 \mathrm{~mm}$ and the flexible adhesive bondline (B) was 2.5 $\mathrm{mm}$. Firstly, the recess length $L$ was kept constant (for the first computation at $6 \mathrm{~mm}$ ) and the effect of variation of recess depth (from 0.4 to $0.8 \mathrm{~mm}$ with the increments of 0.1 $\mathrm{mm}$ ) was investigated. After this, the same procedure was followed to increase the recess length by $1 \mathrm{~mm}$ (up to 9 $\mathrm{mm}$ ). The effects of the recess length and depth on the peel 

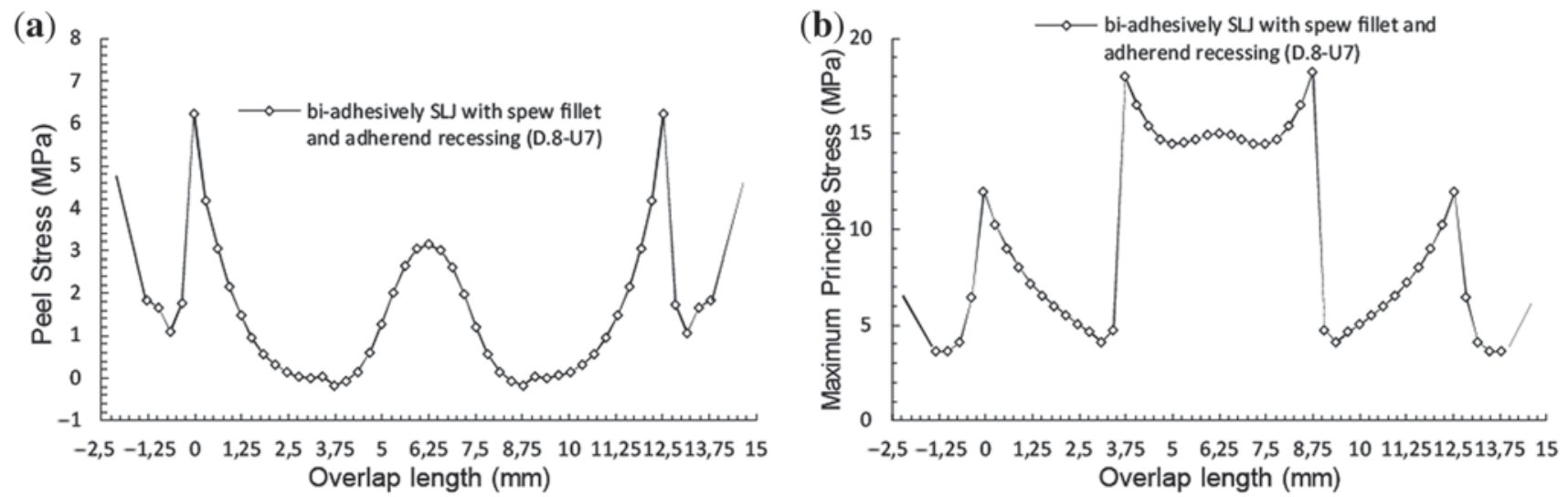

Figure 4. Stress distribution of the interface between the adhesive and the substrate.

stress and MPS distribution in the mid-bondline $(y=0.1$ $\mathrm{mm}$ ) for all Case 1 configurations are depicted in figure 5 .

Increasing the recess length from 6 to $7 \mathrm{~mm}$ when the recess depth was $0.8 \mathrm{~mm}$ increased the peak value of the peel stress by $0.1 \%$; in contrast, MPS decreased by $4.2 \%$. When recess depth was $0.5 \mathrm{~mm}$, the decrease in the peak values of stresses was by only $0.7 \%$ for peel stress and $4.6 \%$ for MPS (see figure 5a and $\mathrm{b}$ ).

If the recess depth was kept constant at $0.8 \mathrm{~mm}$, increasing the recess length from 8 to $9 \mathrm{~mm}$ led to a decrease in the peak values of the peel stress and MPS by $6.8 \%$ and $1.3 \%$, respectively. Minimum decreases in the stress value ratios were observed in the configuration where the recess depth was $0.4 \mathrm{~mm}$; the peak value of stresses decreased only by $3.2 \%$ for peel stress and $0.5 \%$ for MPS. The mentioned changes in the stress values are depicted in figure $5 \mathrm{c}$ and $\mathrm{d}$.

Increasing the recess length from 7 to $8 \mathrm{~mm}$ when the depth was $0.8 \mathrm{~mm}$ decreased the peak values of peel stress by $2.4 \%$ and MPS by $7.7 \%$. Also, setting the recess depth at $0.5 \mathrm{~mm}$ caused a decrease in the values of peel stress and MPS by $1.2 \%$ and $1.9 \%$, respectively (see figure $5 \mathrm{~b}$ and c).

As a result, the optimum peel stress and MPS can be obtained in the case of bi-adhesively bonded SLJs with spew fillet in which the recess depth $(D)$ is $0.8 \mathrm{~mm}$ and the length $(L)$ is $9 \mathrm{~mm}$ (see table $3 \mathrm{a}$ and $\mathrm{b}$ ).

\subsection{Case 2}

In what follows, the flexible and stiff adhesive bond lengths $(B$ and $S$ ) were 3.5 and $5.5 \mathrm{~mm}$, respectively, and all the other geometric dimensions and computation procedures were the same as in Case 1.

Increasing the recess length from 6 to $7 \mathrm{~mm}$ when the recess depth was $0.8 \mathrm{~mm}$ increased the peak value of the peel stress by $0.3 \%$ and decreased the peak value of MPS by $5.5 \%$. When recess depth was $0.6 \mathrm{~mm}$, the decrease in the peak value was only $0.4 \%$ for peel stress and 4.1 for MPS (see figure 6a and b).

If the recess depth was kept constant at $0.8 \mathrm{~mm}$, the peak value of the stresses decreased by $5.8 \%$ for peel stress and $1.2 \%$ for MPS in the condition where the recess length was increased from 8 to $9 \mathrm{~mm}$. When the recess depth was 0.4 $\mathrm{mm}$, the peak value of peel stress decreased $2.2 \%$, in contrast with MPS, which decreased by $3.7 \%$. The mentioned changes in the stress value are depicted in figure $6 \mathrm{c}$ and $\mathrm{d}$.

If the length of recess was enlarged from 7 to $8 \mathrm{~mm}$ and the depth was $0.8 \mathrm{~mm}$, the maximum stress values decreased by $2.3 \%$ for peel stress and $2.2 \%$ for MPS. When the recess depth was set as $0.7 \mathrm{~mm}$, the decrements in the peak value of peel stress and MPS were about $1.6 \%$ (see figure $6 \mathrm{~b}$ and $\mathrm{c}$ ).

Consequently, for this case, the optimum peel stress can be obtained in the case of bi-adhesively bonded SLJs with spew fillet in which the recess depth $(D)$ is $0.8 \mathrm{~mm}$ and the length is $(L) 9 \mathrm{~mm}$ (see table $4 \mathrm{a}$ ). Similarly, the optimum MPS is observed in the case where the recess depth $(D)$ is $0.5 \mathrm{~mm}$ and the length is $(L) 9 \mathrm{~mm}$ (see table 4b).

For the peel stress values of each joint configuration in Case 1 and Case 2, a single peak point occurred in the flexible adhesive when the recess length was 6 or $7 \mathrm{~mm}$. If the recess length was 8 or $9 \mathrm{~mm}$, double peak points were observed (see figures 5 and 6 ).

\section{Discussion and conclusions}

The recessed bi-adhesively bonded SLJ with spew filled in tension has been analysed using 3D FE method considering geometric non-linearity to understand the mechanical characteristics of the graded bond region. Also the influence of various geometrical parameters on the bond strength and the alteration of stress distributions in the midbondline have been investigated. 

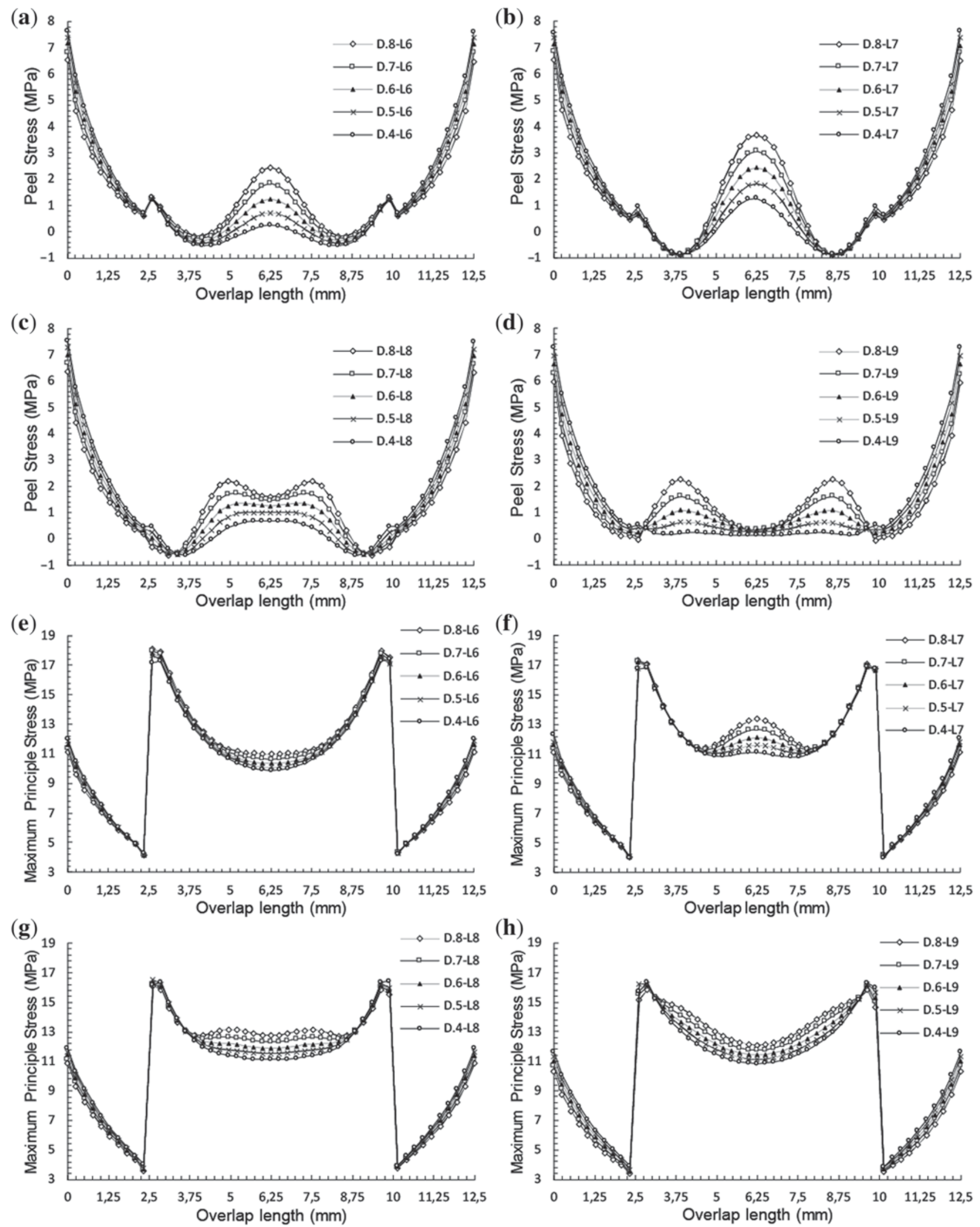

Figure 5. Effect of the recessing depth and length on the 25-75-25 Model (Case 1). 

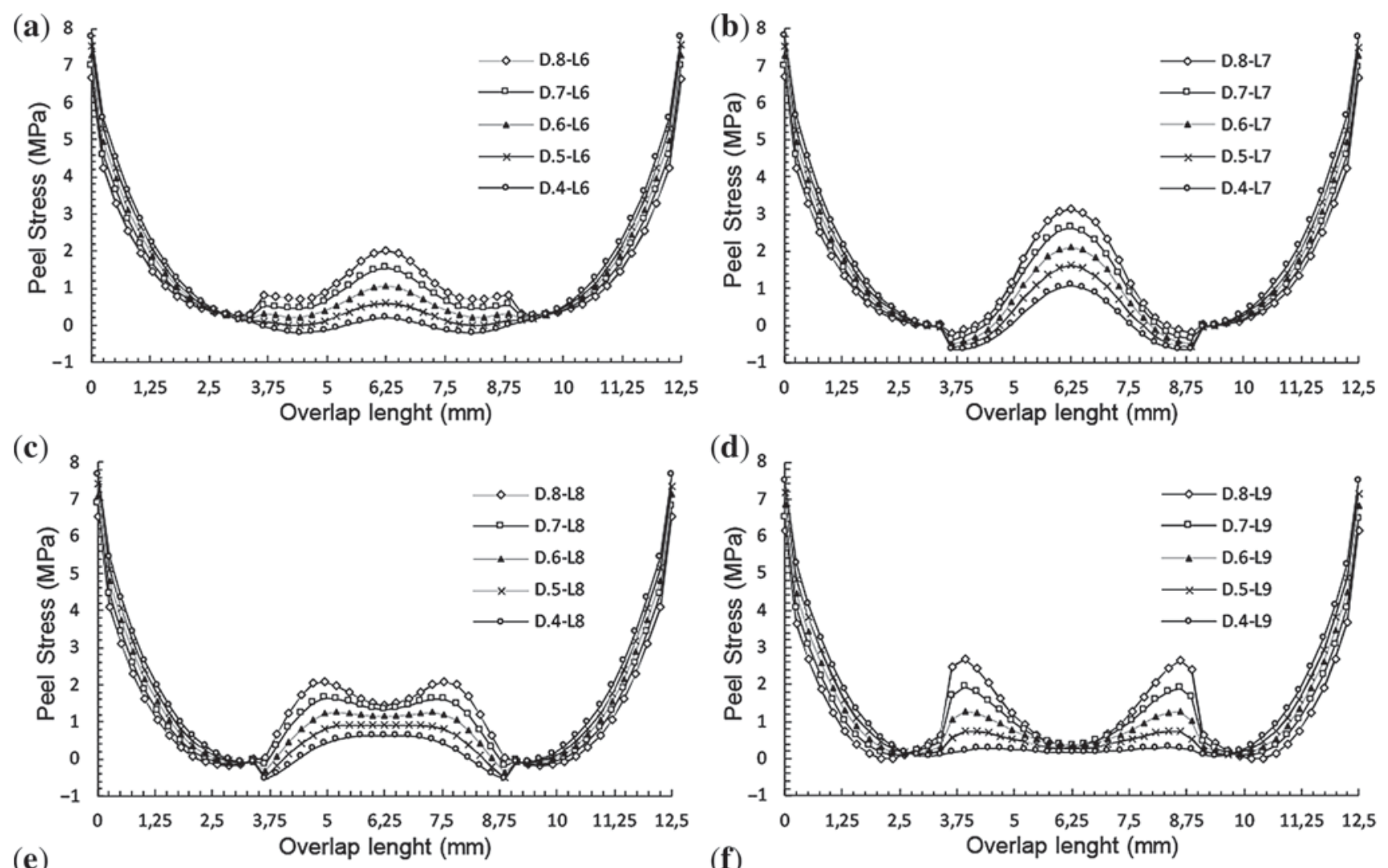

(e)

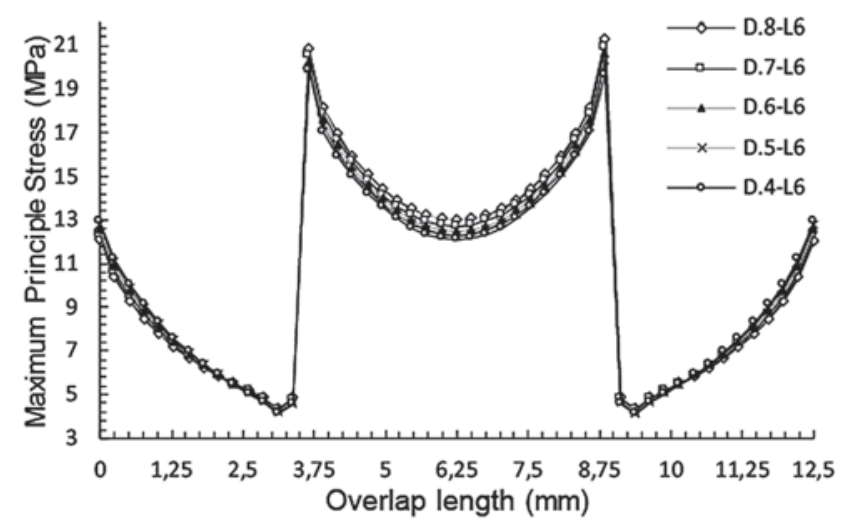

(g)

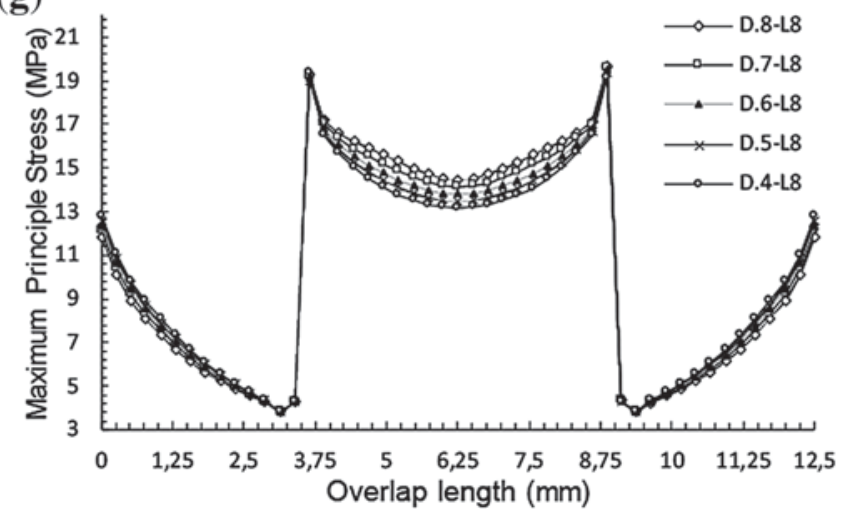

(f)

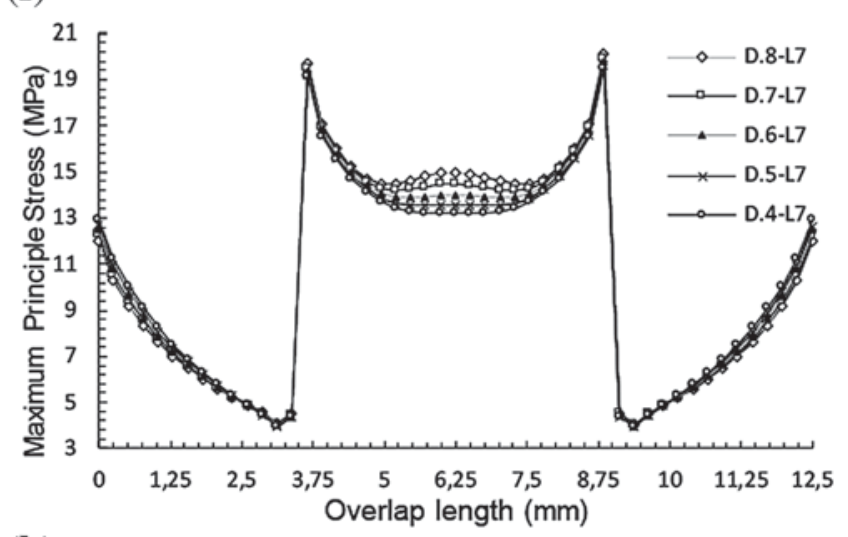

(h)

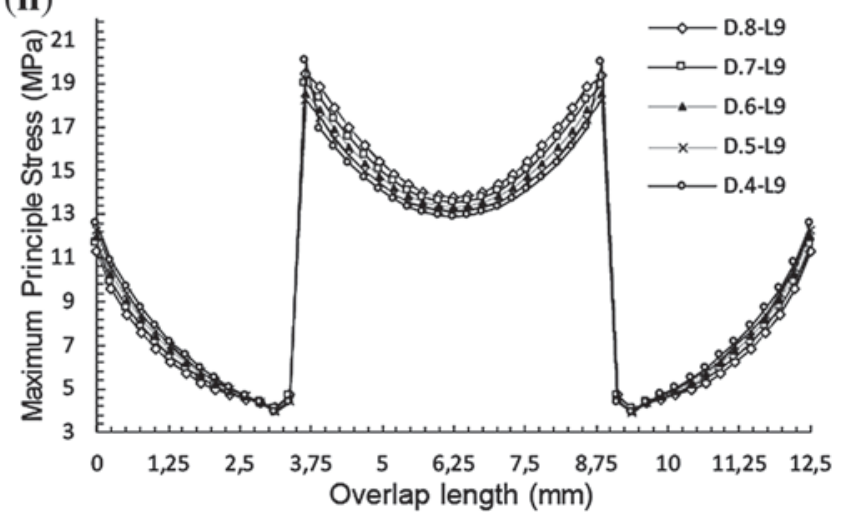

Figure 6. Effect of the recessing depth and length on the 35-55-35 Model (Case 2). 
Table 3. Result of maximum values of MPS and normal stress for Case 1.

\begin{tabular}{|c|c|c|c|c|}
\hline & L6 & L7 & L8 & L9 \\
\hline \multicolumn{5}{|c|}{ (a) Peak values of peel stress } \\
\hline D.8 & 6.5294 & 6.5361 & 6.3806 & 5.9447 \\
\hline D.7 & 6.8330 & 6.8447 & 6.6995 & 6.2865 \\
\hline D.6 & 7.1673 & 7.1309 & 6.9902 & 6.6466 \\
\hline D. 5 & 7.4119 & 7.3613 & 7.2748 & 6.9674 \\
\hline D.4 & 7.6316 & 7.6357 & 7.5194 & 7.2801 \\
\hline \multicolumn{5}{|c|}{ (b) Peak values of MPS } \\
\hline D.8 & 18.105 & 17.343 & 16.087 & 15.877 \\
\hline D.7 & 17.951 & 17.270 & 16.251 & 16.048 \\
\hline D.6 & 17.811 & 17.213 & 16.398 & 16.167 \\
\hline D. 5 & 17.677 & 16.862 & 16.535 & 16.257 \\
\hline D.4 & 17.437 & 16.860 & 16.446 & 16.365 \\
\hline
\end{tabular}

Table 4. Result of maximum values of peel stress and MPS for Case 2.

\begin{tabular}{|c|c|c|c|c|}
\hline & L6 & L7 & L8 & L9 \\
\hline \multicolumn{5}{|c|}{ (a) Peak values of the peel stress } \\
\hline D.8 & 6.6743 & 6.6932 & 6.5381 & 6.1568 \\
\hline D.7 & 6.9787 & 6.9763 & 6.8661 & 6.5089 \\
\hline D.6 & 7.2869 & 7.2602 & 7.1411 & 6.8438 \\
\hline D.5 & 7.5472 & 7.5237 & 7.3985 & 7.1595 \\
\hline D. 4 & 7.7672 & 7.8022 & 7.6574 & 7.4901 \\
\hline \multicolumn{5}{|c|}{ (b) Peak values of MPS } \\
\hline D.8 & 21.269 & 20.107 & 19.656 & 19.429 \\
\hline D.7 & 20.923 & 19.924 & 19.599 & 18.976 \\
\hline D.6 & 20.614 & 19.762 & 19.514 & 18.579 \\
\hline D.5 & 20.323 & 19.615 & 19.343 & 18.243 \\
\hline D.4 & 19.832 & 19.523 & 19.314 & 20.040 \\
\hline
\end{tabular}

The results can be summarized as follows.

- Increasing the recess length $L$ while keeping constant the recess depth $D$ decreases the values of peel stress of the mid-bond plane by up to $22.5 \%$ for the configurations having longer stiff adhesive (Case 1) in comparison with the configurations having shorter stiff adhesive (Case 2). Similarly, increasing the recess depth $D$ while keeping constant the recess length $L$ decreases the values of peel stress in the mid-bond plane by only up to $3.5 \%$ for Case 1 in comparison with Case 2.

- Increasing the length $L$ from 6 to $9 \mathrm{~mm}$ with the increments of $1 \mathrm{~mm}$ for all configurations of Case 1 and Case 2 (except for D. 4 configurations of Case 2) decreases the MPS in the mid-bondline.

- Increasing the depth $D$ from 0.4 to $0.8 \mathrm{~mm}$ with the increments of $0.1 \mathrm{~mm}$ for the configurations where length $L=6$ and $7 \mathrm{~mm}$ of Case 1 and $L=6,7$ and 8 $\mathrm{mm}$ of Case 2 decreases the MPS in the mid-bondline, in contrast with configurations where $L=8$ and $9 \mathrm{~mm}$ of Case 1 and $L=9 \mathrm{~mm}$ of Case 2, in which the MPS increases.

- For all configurations of both cases, the peaked peel stress in Case 1 is approximately $2.27 \%$ lower than in Case 2 and peaked MPS in Case 1 is $15 \%$ lower than in Case 2.

- The peak value of peel stress always occurs at the end of overlap length and the peak value of MPS is always observed at the merging interface of stiff and flexible adhesives.

- The bond length and recessing geometry ratios are two important parameters and proper combination of these yields optimal stress distributions in the bond area.

\section{References}

[1] Ouinas D 2012 Strength of aluminium single-lap bonded joints in various disbond size at circular and semi-circular notches. J. Sandwich Struct. Mater. 14(6): 753-768

[2] Doru M O, Özel A, Akpinar S and Aydin M D 2013 Effect of the spew fillet on adhesively bonded single-lap joint subjected to tensile loading: experimental and 3-D non-linear stress analysis. J. Adhes. 90(3): 195-209

[3] Zehsaz M, Vakili-Tahami F and Saeimi-Sadigh M A 2014 Creep analysis of adhesively bonded single lap joint using finite element method. J. Mech. Sci. Technol. 28(7): 2743-2748

[4] Brockmann W, Geiß P, Klingen J, Schröder B and Mikhail B 2009 Adhesive bonding. Weinheim: Wiley-VHC

[5] He X 2011 A review of finite element analysis of adhesively bonded joints. Int. J. Adhes. Adhes. 31(4): 248-264

[6] Nemes O and Lachaud F 2009 Modeling of cylindrical adhesively bonded joints. J. Adhes. Sci. Technol. 23(10-11): 1383-1393

[7] Her S C 1999 Stress analysis of adhesively-bonded lap joints. Compos. Struct. 47(1): 673-678

[8] Gleich D, Van Tooren M and Beukers A 2001 Analysis and evaluation of bondline thickness effects on failure load in adhesively bonded structures. Int. J. Adhes. Adhes. 15(9): 1091-1101

[9] Lang T and Mallick P 1998 Effect of spew geometry on stresses in single lap adhesive joints. Int. J. Adhes. Adhes. 18(3): 167-177

[10] Tsai M and Morton J 1995 The effect of a spew fillet on adhesive stress distributions in laminated composite singlelap joints. Compos. Struct. 32(1): 123-131

[11] Akpinar S, Doru M O, Özel A, Aydin M D and Jahanpasand H G 2013 The effect of the spew fillet on an adhesively bonded single-lap joint subjected to bending moment. Composites B: Eng. 55: 55-64

[12] Belingardi G, Goglio L and Tarditi A 2002 Investigating the effect of spew and chamfer size on the stresses in metal/plastics adhesive joints. Int. J. Adhes. Adhes. 22(4): 273-282

[13] You M, Zheng Y, Zheng X L and Liu W J 2003 Effect of metal as part of fillet on the tensile shear strength of 
adhesively bonded single lap joints. Int. J. Adhes. Adhes. 23(5): 365-369

[14] Fessel G, Broughton J, Fellows N, Durodola J and Hutchinson A 2007 Evaluation of different lap-shear joint geometries for automotive applications. Int. J. Adhes. Adhes. 27(7): 574-583

[15] Pires I, Quintino L and Miranda R 2006 Numerical simulation of mono-and bi-adhesive aluminium lap joints. J. Adhes. Sci. Technol. 20(1): 19-36

[16] Sato C and Ikegami K 2000 Dynamic deformation of lap joints and scarf joints under impact loads. Int. J. Adhes. Adhes. 20(1): 17-25

[17] Fitton M and Broughton J 2005 Variable modulus adhesives: an approach to optimised joint performance. Int. J. Adhes. Adhes. 25(4): 329-336

[18] Adin H and Temiz Ş 2014 Experimental and numerical strength analysis of double lap joints subjected to tensile loads. Mater. Test. 56(2): 160-168

[19] Aydin M D, Özel A and Temiz Ş 2004 Non-linear stress and failure analyses of adhesively-bonded joints subjected to a bending moment. J. Adhes. Sci. Technol. 18(14): 1589-1602

[20] Tang J H, Sridhar I and Srikanth N 2013 Static and fatigue failure analysis of adhesively bonded thick composite single lap joints. Compos. Sci. Technol. 86: 18-25

[21] Ozel A, Yazici B, Akpinar S, Aydin M D and Temiz Ş 2014 A study on the strength of adhesively bonded joints with different adherends. Composites B: Eng. 62: 167-174

[22] Akpinar S, Temiz Ş, Aydin M D and Özel A 2012 Effect of protrusion at the ends of bondline in single lap joints under tension and bending. J. Adhes. Sci. Technol. 26(23): 2591-2602

[23] Apalak Z G, Apalak M K and Davies R 1996 Analysis and design of adhesively bonded tee joints with a single support plus angled reinforcement. J. Adhes. Sci. Technol. 10(8): 681-724

[24] Gültekin K, Akpinar S and Özel A 2015 The effect of moment and flexural rigidity of adherend on the strength of adhesively bonded single lap joints. J. Adhes. 91(8): 637-650

[25] İşcan B 2015 Strength of lap joints with embedded cover plate. J. Mech. Sci. Technol. 29(5): 2105-2110

[26] Solmaz M Y and Topkaya T 2013 Progressive failure analysis in adhesively, riveted, and hybrid bonded double-lap joints. J. Adhes. 89(11): 822-836

[27] Pinto A M G, Ribeiro N F Q R, Campilho R D S G and Mendes I R 2014 Effect of adherend recessing on the tensile strength of single lap joints. J. Adhes. 90(8): 649-666

[28] Afkar A and Camari M N 2014 Finite element analysis of mono- and bi-adhesively bonded functionally graded adherend. J. Fail. Anal. Prev. 14(2): 253-258

[29] Özer H and Öz Ö 2014 A comparative evaluation of numerical and analytical solutions to the biadhesive singlelap joint. Math. Probl. Eng. 2014: 1-16

[30] Kumar S and Pandey P C 2010 Behaviour of bi-adhesive joints. J. Adhes. Sci. Technol. 24(7): 1251-1281

[31] Luo Q and Tong L 2015 Solutions for clamped adhesively bonded single lap joint with movement of support end and its application to a carbon nanotube junction in tension. $J$. Adhes. 92(5): 349-379 